\title{
PENGARUH EFIKASI DIRI, KEPEMIMPINAN, MOTIVASI DAN FASILITAS KERJA TERHADAP KINERJA PEGAWAI KANTOR PELAYANAN PAJAK PRATAMA PEKANBARU SENAPELAN
}

\author{
Fauziah Rahmi \\ Universitas Islam Sumatera Utara \\ fauziah.rahmi@gmail.com
}

\begin{abstract}
The problem in this research is: Does the self-efficacy, leadership, motivation and work facilities partially and simultaneously affect the performance of Pekanbaru Senapelan Primary Service Office employees? Research Objectives: To find out whether self-efficacy, leadership, motivation and work facilities partially and simultaneously simultaneously affect the performance of Pekanbaru Senapelan Tax Office. The hypothesis proposed is: There is an effect of self-efficacy, leadership, motivation and work facilities partially and jointly on the performance of Pekanbaru Primary Tax Service Office Senapelan Research conducted at the Pekanbaru Primary Tax Office Senapelan Jalan Sudirman Number 247 Simpang Empat Pekanbaru, with a population of 110 people, and a sample of 86 people.Based on the analysis results obtained there is a significant effect between self-efficacy on the performance of the Pelanbaru Senapelan Tax Office employee, because according to the results of the analysis of $t$ count $>t$-table $(3.159>1.67)$ at $n=93$ with $a$ significance level of 95\%. There is a significant influence between leadership on the performance of Pelanbaru Senapelan Tax Office employees, the results of t-analysis>t-table $(2,439>1.67)$ at $n$ $=93$ with a significance level of $95 \%$. There is a significant influence between work motivation towards the performance of the Pelanbaru Senapelan Primary Tax Office employee, because according to the results of the analysis of $t$ count $>t$-table (1.762>1.67) at $n=58$ with $a$ significance level of 95\%. There is a significant influence between work facilities on the performance of the employees of the Senapelan Pelanbaru Tax Office, because according to the analysis of tcount> $t$-table (3.897> 1.67) at $n=93$ with a significance level of $95 \%$. F-count value $>F$ table $(178.340>2.46)$ together (multiple) there is a positive and significant influence of self-efficacy, leadership, motivation and work facilities on the performance of employees of the Pelanbaru Senapelan Tax Office. Thus the hypothesis proposed is accepted
\end{abstract}

Keyworld: Self-efficacy, leadership, motivation and work facilities and employee performance.

ABSTRAK :Masalah dalam peneltian ini adalah:Apakah efikasi diri, kepemimpian, motivasi dan fasilitas kerja secara parsial dan bersamaan berpengaruh terhadap kinerja pegawai Kantor Pelayanan Pratama Pekanbaru Senapelan? Tujuan peneitian : Untuk mengetahui apakah efikasi diri, kepemimpinan, motivasi dan fasilitas kerja secara parsial dan bersamaan bersamaan berpengaruh terhadap kinerja pegawai Kantor Pelayanan Pajak Pratama Pekanbaru Senapelan.Hipotesis yang diajukan adalah : Ada pengaruh efikasi diri, kepemimpinan, motivasi dan fasilitas kerja secara parsial dan bersama-sama bersama-sama terhadap kinerja pegawai Kantor Pelayanan Pajak Pratama Pekanbaru Senapelan Penelitian dilakukan di Kantor Pelayanan Pajak Pratama Pekanbaru Senapelan Jalan Sudirman Nomor 247 Simpang Empat Pekanbaru, dengan populasi sebanyak110 orang, dan sampel penelitian sebanyak 86 orang.Berdasarkan hasil analisis diperoleh Ada pengaruh yang signifikan antara efikasi diri terhadap kinerja pegawai Kantor Pelayanan Pajak Pratama Pelanbaru Senapelan, karena menurut hasil analisis thitung $>t$ tabel $(3,159>1,67)$ pada $n=93$ dengan taraf sifgifikansi 95\%.Ada pengaruh yang signifikan antara kepemimpinan terhadap kinerja pegawai Kantor Pelayanan Pajak Pratama Pelanbaru Senapelan, hasil analisis thitung > t-tabel $(2,439>1,67)$ pada $n=93$ dengan taraf sifgnifikansi 95\%.. Ada pengaruh yang signifikan antara motivasi kerja terhadap kinerja pegawai Kantor Pelayanan Pajak Pratama Pelanbaru Senapelan, karena menurut hasil analisis thitung > t-tabel $(1,762>1,67)$ pada $n=58$ dengan taraf sifgnifikan 95\%. Ada pengaruh yang signifikan antara 
fasilitas kerja terhadap kinerja pegawai Kantor Pelayanan Pajak Pratama Pelanbaru Senapelan, karena menurut hasil analisis thitung > t-tabel $(3,897>1,67)$ pada $n=93$ dengan taraf sifgifikan 95\%.Nilai F-hitung > F tabel $(178,340>2,46)$ secara bersama-sama (multiple) terdapat pengaruh positif dan signifikan efikasi diri, kepemimpinan,motivasi dan Fasilitas kerja terhadap kinerja pegawai Kantor Pelayanan Pajak Pratama Pelanbaru Senapelan. Dengan demikian hipotesis yang diajukan diterima kebenarannya

Keyworld : Eikasi diri, kepemimpinan, motivasi dan fasilitaskerja serta kinerja pegawai.

\section{Pendahuluan}

Organisasi merupakan wadah atau tempat orang saling bekerja sama dalam melaksanakan kegiatan-kegiatan dalam rangka pencapaian tujuan yang telah ditetapkan sebelumnya. Organisasi juga dipandang sebagai jaringan dari hubungan kerja yang bersifat formal seperti yang tergambar dalam suatu bagan dengan mempergunakan kotak-kotak yang beraneka ragam. Kotak-kotak tersebut memberikan gambaran-gambaran tentang kedudukan atau jabatan yang harus diisi oleh orang-orang yang memenuhi persyaratan semua dengan fungsi masing-masing. Selanjutnya dalam setiap organisasi tidak lepas dari adanya sumber daya manusianya. Sumber daya manusia merupakan penggerak utama dalam suatu organisasi.Kunci keberhasilan sebuah organisasi adalah pada sumber daya manusia yaitu sebagai inisiator, pemberi tenaga, kreativitas dan usaha mereka kepada organisasi untuk meningkatkan kemampuan perubahan organisasi secara terusmenerus.Pegawai yang ada dalam organisasi memiliki Kinerja dan hal ini sangat penting dan sangat menentukan keberhasilan organisasi.Kinerja merupakan suatu unsur yang sangat penting, untuk melihat sejauh mana hasil kerja yang dicapai oleh pegawai didalam pelaksanaan kegiatan kerjanya yang telah ditetapkan oleh pimpinan. Kinerja merupakan pengertian relatif yang melukiskan keadaan yang lebih baik dibandingkan dengan keadaan sebelumnya.. Menurut Ndraha (2012:44) Kinerja adalah suatu sikap mental yang selalu berusaha dan mempunyai pandangan bahwa mutu kehidupan hari ini harus lebih baik dari hari kemarin dengan hari esok lebih baik dari hari ini. Dengan demikian setiap organisasi senantiasa mengharapkan kinerja pegawainya dengan baik, begitu juga Kinerja di Kantor Pelayanan Pajak Pratama Pekanbaru Senapelan belum tercapai secara maksimal, hal ini disebabkan rendahnya efikasi diri pegawai, kepemimpinan yang kurang demokratis, rendahnya motivasi pegawai kurang baiknya fasilitas kerja.
Agar kinerja pegawai di Kantor Pelayanan Pajak Pratama Pekanbaru Senapelan, maka pimpinan organisasi perlu memperhatikan efikasi diri (keyakinan diri)dari personelnya.Mangkunegara.(2009:35)

mengatakan efikasi diri adalah keyakinan seseorang mengenai peluangnya untuk berhasil dalam mencapai tugas tertentu. Spears dan Jordon dikutip Maryati (2010:50), yang mengistilahkan keyakinan sebagai efikasi diri yaitu keyakinan seseorang bahwa dirinya akan mampu melaksanakan tingkah laku yang dibutuhkan dalam suatu tugas. Bandura (dalam Nurchasanah: (2011:50) menyatakan bahwa self-efficacy adalah kepercayaan seseorang bahwa dia dapat menjalankan sebuah tugas pada sebuah tingkat tertentu, yang mempengaruhi aktifitas pribadi terhadap pencapaian tujuan yang ditetapkan. Dengan keyakinan diriyang tinggi maka pegawai akan berupaya mengerjakan tugas yang sulit dengan tetap tenang dan tidak cemas.

Kepemimpinan sangat besar perannya dalam organisasi.Mengusahakan pegawai agar mereka memiliki kemauan serta memiliki kesadaran maupun tanggung jawab yang tinggi diperlukan usaha managerial yang dimaksudkan untuk mengelola pegawai-pegawai dalam melakukan pekerjaan. Usaha-usaha managerial ini sesuai apa yang dikemukakan oleh Terry Manajemen adalah suatu proses yang khas yang terdiri dari tindakan planning, organizing, actuating serta controlling dimana pada masing-masing bidang digunakan baik ilmu pengetahuan maupun keahlian dan diikuti secara beruntun dalam rangka pencapaian sasaran yang telah ditetapkan semula. salah satu aplikasi manajemen itu adalah dengan melakukan penggerakan pegawai agar mereka dapat melaksanakan aktivitas kerja secara fisik yang diarahkan oleh pimpinan dengan memberikan perintah, memperbaiki hasil kerja mereka serta untuk menimbulkan rasa percaya diri dalam melakukan kreativitas kerja mereka. Untuk keperluan itulah pegawai digerakkan oleh pimpinan sehingga tercipta pegawai yang selain 
berkwalitas juga memiliki kemauan serta tanggung jawab terhadap pekerjaan yang dibebankan kepadanya maupun tanggung jawab yang lebih besar

Sebagai daya pendorong yang merangsang pegawai untuk mau bekerja dengan giatnya berbeda antara pegawai yang satu dengan pegawai yang lain. Perbedaan itu disebabkan oleh perbedaan motif, tujuan dan kebutuhan masing-masing pegawai.Bagi setiap pegawai motivasi tidak hanya berwujud kebutuhan ekonomi saja, tetapi bisa berbentuk penghargaan dari lingkungan, prestasi, status sosial yang semuanya merupakan ganjaran sosial yang non materil sifatnya. Karena manusia tidak sama dengan mesin, maka harus senantiasa dimotivasi untuk bekerja. Pimpinan tidak dapat mengharapkan bahwa motivasi pegawai akan muncul secara spontan. Motivasi berkaitan erat dengan kebutuhan pegawai oleh karena itu pemberian motivasi harus bertitik tolak dari kebutuhan pegawai itu sendiri. Pemberian motivasi yang tidak sesuai hanya akan memberikan kekecewaan bagi si pegawai itu sendiri.

Selanjutnya pegawai sebagai sumber daya manusia yang tidak terampil maupun yang terampil dan cakap memiliki kebutuhan yang sangat kompleks. Untuk memenuhi kebutuhan tersebut pegawai bekerja dan menerima upah atau gaji.Selain upah dan gaji mereka juga menuntut suatu kepuasan batin dalam bekerja, dimana kepuasaan ini diperoleh melalui fasilitas fasilitas seperti fasilitas kerja, kesehatan, perumahan. Apabila ini tidak terpenuhi akan menimbulkan suatu kontradiksi dari berbagai pihak, seperti pemerintah, organisasi buruh, terutama pegawai itu sendiri, bahkan kemungkinan organisasi internasional akan turut mencampurinya. Apabila ini terjadi dan tidak dapat diatasi maka akan mengakibatkan kerugian yang besar bagi organisasi yang berakhir pada berhentinya kegiatan dan operasional setiap organisasi. Dengan demikian tujuan organisasi yang telah ditetapkan tidak akan dapat tercapai.

Mengusahakan pegawai agar mereka memiliki kemauan serta memiliki kesadaran maupun tanggung jawab yang tinggi diperlukan usaha managerial yang dimaksudkan untuk mengelola pegawai-pegawai dalam melakukan pekerjaan. Usaha-usaha managerial ini sesuai apa yang dikemukakan oleh Terry Manajemen adalah suatu proses yang khas yang terdiri dari tindakan planning, organizing, actuating serta controlling dimana pada masing-masing bidang digunakan baik ilmu pengetahuan maupun keahlian dan diikuti secara beruntun dalam rangka pencapaian sasaran yang telah ditetapkan semula. salah satu aplikasi manajemen itu adalah dengan melakukan penggerakan pegawai agar mereka dapat melaksanakan aktivitas kerja secara fisik yang diarahkan oleh pimpinan dengan memberikan perintah, memperbaiki hasil kerja mereka serta untuk menimbulkan rasa percaya diri dalam melakukan kreativitas kerja mereka. Untuk keperluan itulah pegawai digerakkan oleh pimpinan sehingga tercipta pegawai yang selain berkwalitas juga memiliki kemauan serta tanggung jawab terhadap pekerjaan yang dibebankan kepadanya maupun tanggung jawab yang lebih besar

Hal-hal yang disebutkan di atas tersebut tidak akan terjadi apabila organisasi memperhatikan tuntutan dan memenuhi kebutuhan para pegawai tersebut. Sebaliknya jika organisasi terutama pemimpin memperhatikan dan memenuhi kebutuhan para pegawai mereka akan bekerja lebih bergairah dan akan berpengaruh terhadap kelancaran pelaksanaan tugas sehingga dapat meningkatkan hasil kerja. Hal ini dicapai apabila organisasi memandang pegawai sebagai suatu sumber daya manusia yang sangat vital dan tidak dapat dipisahkan dari kegiatan organisasi.Oleh sebab itu organisasi harus meningkatkan kualitas dan kemampuan sumber daya manusia tersebut dengan terlebih dahulu selain memberikan gaji kepada pegawai juga menyediakan fasilitas-fasilitas lainnya. Dengan demikian para pegawai termotivasi untuk bekerja lebih baik dan akan mempengaruhi kelancaran pelaksanaan tugas masing-masing pegawai.

Berdasarkan identifikasi dan rumusan masalah di atas maka penelitian ini adalah sebagai berikut:

1. Untuk mengetahui bagaimana pengaruh efikasi diri terhadap kinerja pegawai Kantor Pelayanan Pajak Pratama Pekanbaru Senapelan.

2. Untuk menganalisis dan mengetahui apakah kepemimpinan berpengaruh terhadap kinerja pegawai Kantor Pelayanan Pajak Pratama Pekanbaru Senapelan

3. Untuk menganalisis dan mengetahui apakah motivasi berpengaruh terhadap kinerja pegawai Kantor Pelayanan Pajak Pratama Pekanbaru Senapelan 
4. Untuk menganalisis dan mengetahui pengaruh fasilitas kerja berpengaruh terhadap kinerja pegawai Kantor Pelayanan Pajak Pratama Pekanbaru Senapelan

5. Untuk mengetahui apakah efikasi diri, kepemimpinan, motivasi dan fasilitas kerja secara bersamaan berpengaruh terhadap kinerja pegawai Kantor Pelayanan Pajak Pratama Pekanbaru Senapelan.

\section{Metode Penelitian}

\subsection{Lokasi Penelitian}

Lokasi penelitian adalah para pegawai

Kantor Pelayanan Pajak Pratama Pekanbaru Senapelan Jalan Sudirman Nomor 247 Simpang Empat Pekanbaru.

\subsection{Populasi dan Sampel}

Populasi penelitian ini seluruh pegawai Kantor Pelayanan Pajak Pratama Pekanbaru Senapelan sebanyak 110 orang, Sampel adalah bagian dari jumlah dan karakteristik yang dimiliki oleh populasi. Sampel penelitian dapat ditetapkan ketentuan Arikunto, (2010:120) yaitu :"apabila populasi kurang dari 100 orang, lebih baik diambil semua sehingga penelitian merupakan penelitian populasi. Jika jumlah subjeknya lebih dari 100 orang, dapat diambil $10-15 \%$ atau $20-25 \%$ atau lebih." Sebagaimana disebutkan di atas bahwa populasi sebanyak 110 orang maka sampel diambil sebanyak $86 \%$ (95 orang).

\subsection{Teknik Analisa Data}

Teknik analisis data menggunakan validitas dan realibilitas, uji asumsi klasik dengan menggunakan uji Multikolinearitas, Multikolinearitas, Uji Heteroskedastisitas. Pengujian Hipotesis menggunakan uji regresi berganda.

\section{Hasil dan Pembahasan \\ 3.1. Analisis Regresi}

Analisis regresi digunakan untuk menganalisis data hasil penelitian dengan maksud untuk memperoleh gambaran hubungan fungsional antara variabel bebas dengan variabel terikat hal ini dengan menggunakan analisis regresi linier berganda

Berdasarkan analisis regresi linier ganda (Multiple) sebagaimana pada lampiran 10 diperoleh koefisien regresi sebagai berikut.

Tabel 1

Koefisien Regresi

\begin{tabular}{|c|c|c|c|c|c|}
\hline \multirow[b]{2}{*}{ Moc } & & \multicolumn{2}{|c|}{ Unstandardized Coefficients } & \multirow{2}{*}{$\begin{array}{c}\begin{array}{l}\text { Standardized } \\
\text { Coefficients }\end{array} \\
\text { Beta }\end{array}$} & \multirow{2}{*}{$\mathrm{T}$} \\
\hline & & B & Std. Error & & \\
\hline \multirow{5}{*}{1} & (Constant) & 5.633 & 1.207 & & 4.667 \\
\hline & Efikasi Diri & .248 & .078 & .270 & 3.159 \\
\hline & Kepemimpinan & .154 & .063 & .153 & 2.439 \\
\hline & Motivasi & .173 & .087 & .182 & 1.985 \\
\hline & Fasilitas Kerja & .386 & .099 & .390 & 3.897 \\
\hline
\end{tabular}

Sumber : Hasil Pengolahan Data, 2019

Berdasarkan Tabel 5.18diperoleh koefisien regresi variabel Efikasi Diri 0,248, Kepemimpinan 0,154, Motivasi $=0,173$, Fasilitas kerja 0,386 dengan konstanta 5,633, maka dapat dituliskan persamaan regresi sebagai berikut.

$$
Y=5,633+\underset{0,248 X_{1}+0,154 X_{2}+0,173 X_{3}+}{0,386 X_{4}+1,40}
$$

Persamaan di atas menunjukkan konstanta bernilai positip dan nilai koefisien regresi juga positip.Hal ini memberi gambaran bahwa perubahan rata-rata variabel kinerja pegawai (Y) tergantung dari perubahan variabel Efikasi Diri $\left(\mathrm{X}_{1}\right)$, Kepemimpinan $\left(\mathrm{X}_{2}\right)$, Motivasi $\left(\mathrm{X}_{3}\right)$. dan fasilitas kerja $\left(\mathrm{X}_{4}\right)$. Artinya apabila efikasi diri, kepemimpinan, motivasi, Fasilitas kerja ditingkatkan akan diikuti perubahan/peningkatan kinerja pegawai. Perubahan ini merupakan peningkatan apabila bertanda positip dan penurunan atau pengurangan jika bertanda negatif.Hal ini menunjukkan bahwa ada pengaruh efikasi diri, kepemimpinan, motivasi dan fasilitas kerja terhadap kinerja pegawai.

\subsection{Uji T (Secara Parsial)}

Untuk mengetahui pengaruh variabel bebas secara parsial terhadap variabel terikat digunakan uji t, dimana dengan ketentuan : 
t- hitung $\leq \mathrm{t}$ - tabel tidak ada pengaruh variabel bebas secara tersendiri terhadap variabel terikat

t- hitung > t- tabel ada pengaruh variabel bebas secara tersendiri terhadap variabel terikat derajat kebebasan $(\mathrm{dk})=\mathrm{n}-2$ dan Tingkat kepercayaan $\alpha=0,05$,

Tabel 2

Uji T (Secara Parsial)

Coefficients $^{\mathrm{a}}$

\begin{tabular}{|c|c|c|c|c|c|c|}
\hline \multirow{2}{*}{\multicolumn{2}{|c|}{ Model }} & \multicolumn{2}{|c|}{ Unstandardized Coefficients } & \multirow{2}{*}{$\begin{array}{c}\begin{array}{c}\text { Standardized } \\
\text { Coefficients }\end{array} \\
\text { Beta }\end{array}$} & \multirow[b]{2}{*}{$\mathrm{T}$} & \multirow[b]{2}{*}{ Sig. } \\
\hline & & B & Std. Error & & & \\
\hline \multirow[t]{5}{*}{1} & (Constant) & 5.633 & 1.207 & & 4.667 & .000 \\
\hline & Efikasi Diri & .248 & .078 & .270 & 3.159 & .002 \\
\hline & Kepemimpinan & .154 & .063 & .153 & 2.439 & .017 \\
\hline & Motivasi & .173 & .087 & .182 & 1.985 & .050 \\
\hline & Fasilitas Kerja & .386 & .099 & .390 & 3.897 & .000 \\
\hline
\end{tabular}

a. Dependent Variable: Kinerja Pegawai

Berdasarkan tabel 5.18. di atas diperoleh nilai t Efikasi Diri $=3,159$, sedangkan t-tabel dengan dk 93 (terlampir) sebesar 1,67 maka t hitung $>$ t-tabel dengan demikian secara parsial ada pengaruh yang signifikan antara Efikasi Diri terhadap kinerja pegawai. Nilai $t$ Kepemimpinan $=2,439$, sedangkan t-tabel dengan dk 93 (terlampir) sebesar 1,67 maka t hitung $>\mathrm{t}$ tabel dengan demikian secara parsial ada pengaruh yang signifikan antara Kepemimpinan terhadap kinerja pegawai.Selanjutnya nilai t Motivasi $=1,985$, sedangkan t-tabel dengan $\mathrm{dk} 93$ (terlampir) sebesar 1,67 maka t hitung > t tabel dengan demikian secara parsial ada pengaruh yang signifikan antara Motivasi terhadap kinerja pegawai. Nilai t Fasilitas kerja $=3,897$, sedangkan t-tabel dengan $\mathrm{dk} 95$ (terlampir) sebesar 1,67 maka t hitung > t tabel dengan demikian secara parsial ada pengaruh yang signifikan antara Fasilitas kerja terhadap kinerja pegawai

\subsection{Uji F (Secara Simultan)}

Berdasarkan analisis varians (Anova) pada lampiran 10dengan hasil sebagai berikut.

Tabel 3

ANOVA Uji - F (secara Simultan)

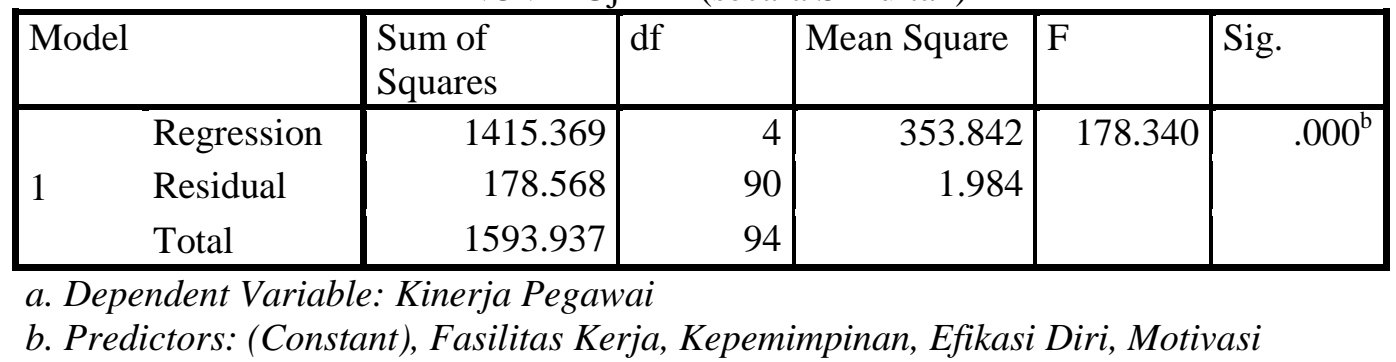

Berdasarkan tabel di atas diketahui nilai Fhitung sebesar 178,340 sedangkan nilai F-tabel (terlampir) dengan $\mathrm{dk}$ pembilang $4 \mathrm{dan} \mathrm{dk}$ penyebut 94 adalah sebesar 2,46 dimana $\mathrm{F}$ hitung > F tabel $(178,340>2,46)$ maka dapat disebutkan bahwa secara bersama-sama (multiple) terdapat pengaruh positif dan signifikan efikasi diri, kepemimpian, Motivasi dan Fasilitas kerja terhadap Kinerja Pegawai .

\subsection{Uji Determinasi}

Berdasarkan hasil analisis data Efikasi Diri di Kantor Pelayanan Pajak Pratama Pekanbaru Senapelan umumnya kurang tinggi, kepemimpinan kurang baik, Motivasi kurang tinggi, dan fasilitas kerja kurang cukup dan Kinerja Pegawai juga rendah.. Kinerja Pegawai dapat meningkat apabila efikasi diri ,Kepemimpinan semakin baik, Motivasi semakin tinggi dan fasilitas kerja semakin cukup karena hasil analisis regresi dan pengujian hipotesis diperoleh terdapat pengaruh 
signifikan efikasi diri, kepemimpinan, motivasi Kerja, Fasilitas kerja terhadap kinerja pegawai. Apabila efikasi diri, kepemimpinan, motivasi kerja, dan Fasilitas kerja ditingkatkan1\% maka kinerja pegawai akan naik $1 \%$. Besarnya pengaruh efikasi diri, kepemimpinan, motivasi

Tabel 3

Model Summary

\begin{tabular}{|l|l|l|l|l|}
\hline Model & R & R Square & $\begin{array}{l}\text { Adjusted R } \\
\text { Square }\end{array}$ & Std. Error of the Estimate \\
\hline 1 & $.942^{\mathrm{a}}$ & .888 & .883 & 1.40858 \\
\hline
\end{tabular}

Berdasarkan tabel 5.20 diperoleh $\mathrm{R}^{2}=0,888$ maka $\mathrm{D}=0,888 \times 100 \%$ sehingga $\mathrm{D}=88,8 \%$. Akan tetapi regresi berganda lebih baik diambil nilai Adjusted R Squsre yakni 88,3\%. Dengan demikian pengaruh efikasi diori, kepemimpinan, Motivasi dan Fasilitas kerja terhadap Kinerja Pegawai Kantor Pelayanan Pajak Pratama Pekanbaru Senapelan sebesar $88,3 \%$. sedangkan $11,7 \%$ lagi yang mempengaruhi Kinerja Pegawai ditentukan faktor lain yang tidak diteliti dalam penelitian ini.

\section{Kesimpulan}

Sesuai hasil analisis penelitian maka dapat diambil kesimpulan sesuai tujuan penelitian yang dikemukakan.

a. Ada pengaruh yang signifikan antara efikasi diri terhadap kinerja pegawai Kantor Pelayanan Pajak Pratama Pelanbaru thitung > t-tabel $(3,159>1,67)$ pada $\mathrm{n}=93$ dengan taraf signifikansi $95 \%$.

b. Ada pengaruh yang signifikan antara kepemimpinan terhadap kinerja pegawai Kantor Pelayanan Pajak Pratama Pelanbaru Senapelan, hasil analisis thitung $>$ t-tabel $(2,439>1,67)$ pada $\mathrm{n}=93$ dengan taraf signifikansi $95 \%$.

c. Ada pengaruh yang signifikan antara motivasi kerja terhadap kinerja pegawai Kantor Pelayanan Pajak Pratama Pelanbaru Senapelan, karena menurut hasil analisis thitung > t-tabel $(1,762>1,67)$ pada $\mathrm{n}=58$ dengan taraf signifikansi $95 \%$

d. Ada pengaruh yang signifikan antara fasilitas kerja terhadap kinerja pegawai Senapelan, karena menurut hasil analisis thitung > t-tabel $(3,897>1,67)$ pada $\mathrm{n}=93$ dengan taraf signifikansi $95 \%$. Senapelan, karena menurut hasil analisis Kantor Pelayanan Pajak Pratama Pelanbaru kerja, Fasilitas kerja terhadap kinerja pegawai dapat diketahui melalui uji determinasi (D) dimana $\mathrm{D}=\mathrm{R}^{2} \times 100 \%$. Hasil analisis pada model summary sebagaimana pada lampiran 10 sebagai berikut.
Nilai F-hitung $>\mathrm{F}$ tabel $(178,340>2,46)$ secara bersama-sama (multiple) terdapat pengaruh positif dan signifikan efikasi diri, kepemimpinan,motivasi dan Fasilitas kerja terhadap kinerja pegawai Kantor Pelayanan Pajak Pratama Pelanbaru Senapelan. Dengan demikian hipotesis yang diajukan diterima kebenarannya.

\section{DAFTAR PUSTAKA}

Barnardin, H. John Joyce E.A. Ressul (2013), Human Resources, Alih Bahasa Triyana, Mc Graw Hill, Inc, Singapore.

Dwiyanto, Agus, 2011, Penilaian Kinerja organisasi Pelayanan

Publik,Yogyakarta : UGM

Garniwa,M. 2010, Kemamapuan

Manajemen,Rineka Cipta, Jakarta

Gie, The Liang, 2013, Administrasi Perkantoran Modern, Yogyakarta: Liberty

Gibson \& Ivancevich \& Donnely. 2015. Organisasi dan manajemen. Perilaku, struktur, proses.Edisi keempat. Erlangga, Jakarta

Handayaningrat, Soewarno, 2014, Pengantar Ilmu Administrasi dan

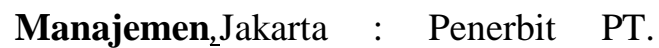
Gunung Agung

Handoko, T. Hani, 2010, Manajemen, BPFE, Yogyakarta, 2012, Manajemen Personalia dan Sumber Daya Manusia, Edisi 2, BPFE, Yogyakarta

Hasibuan, Malayu, SP 2012, Manajemen Sumber Daya Manusia,PT.Bumi Akasara Jakarta.

Komaruddin 2013, Ensiklopedia Manajemen, Rineka Cipta, Jakarta

Maryati, Ika. 2010. Hubungan Antara Kecerdasan Emosi, dan Keyakinan Diri (Self Efficacy) dengan, Kreatifitas 
pada Siswa Akselerasi. Skripsi. Surakarta:Universitas Muhammadiyah Surakarta.

Mangkunegara. 2009. Evaluasi Kinerja SDM. Bandung: PT. Refika Aditama.

Manullang 2011, Manajemen Pengantar Ekonomi Instansi, Edisi Revisi, Cetakan Ke Enam Belas, BPFE, Yogyakarta

Martoyo, Susili 2012, Manajemen Sumber

Daya Manusia, Edisi Ketiga, Cetakan Keempat, Ghalia Jakarta

Moenir, A. S, 2013, Pendekatan Manusia dan

Organisasi Terhadap Pembinaan

Kepegawaian. Gunung Agung, Jakarta.

Ndraha, Taliziduhu, 2012, Budaya Organisasi, Jakarta : Rineka Cipta

Nitisemito, Alex S, 2011. Manajemen Personalia, Jakarta : Ghalia Indonesia

Nurchasanah, 2011, Analisis Pengaruh Empowerment, Self, Efficacy dan Budaya organisasi Terhadap Kepuasan, kerja Dalam Meningkatkan Kinerja Karyawan (Studi, Empiris Pada Karyawan PT.Mayora Tbk Regional Jateng dan DIY).Tesis. Tidak Dipublikasikan.

Prawira, S, 2002, Manajemen Mutu Terpadu, Bumi Aksara, Jakarta

Ranupandojo, Heidjrahman, dan Suad Husnan, 2012:

Personalia,Yogyakarta : BPFE

Rivai Veithzal, Dato. Ahmad Fawzi Mohd.Basri, 2014, Performance Appraisal, PT.Rajagrafindo Persada, Jakarta.

Rohani Ahmad, 2012: Pengelolaan Pengajaran, Jakarta : Rineka Cipta

Robbins, Stephen P. 2013.Perilaku Organisasi. Jakarta: PT. Indeks

Sarwoto, 2013, Dasar-Dasar Organisasi dan Manajemen, Jakarta : Ghalia Indonesia.

Sedarmayanti, 2012, Sumber Daya Manusia dan Produktivitas Kerja, Penerbit Ilham Jaya, Bandung.

Siagian, S.P, 2010, Teori Motivasi dan Aplikasinya, Jakarta : Bina Aksara.

Sofyandi dan Garniwa, 2010, Manajemen Sumber Daya Manusia. Yogyakarta: BPFE

Sudjana, 2013, Metoda Statistika, Tarsito, Bandung.

Sugiyono, 2013, Metode Penelitian Kuantitatif, Kualitatif dn R\&D, Cetakan 10, Penerbit Alfabeta Bandung.
Suprianto, 2011, Dasar-Dasar Organisasi dan Manajemen, Jakarta Gunung Agung.

Susilo,Willy, 2011, Motivasi Intrinsik, Jakarta : PT. Vorqistatama Binamega.

Swastha DH, Basu dan Ibnu Sukotjo 2012, Pengantar Bisnis Modern, Edisi Revisi Liberty Yogyakarta

Tangkilisan, Hessel Hogi S, 2012, Manajemen Publik, Jakarta : Grasindo

Thoha, Miftah, 2013. Prilaku Organisasi, Raja Grafindo Persada, Jakarta

Triton PB 2012, Paradigma Baru Manajemen Sumber Daya Manusia, Tugu Yogyakarta.

Wahjono,2010, Manajemen SDM, Ghalia Indonesia, Jakarta.

Wibowo, 2011, Manajemen Prilaku Organisasi, PT. Citra Aditya, Bandung

Wijaya Tony, Cepar Menguasai SPSS Untuk Olah \& Interpretasi Data Penelitian, 2011, Cahaya Atma Yogyakarta. 